\title{
PLC based Smart Street Lighting Control
}

\author{
Dr. D.V.Pushpa Latha \\ Department of Electrical Engineering, GokarajuRangaraju Institute of Engineering and Technology, Hyderabad, \\ Andhra Pradesh, India \\ E-mail:dvplatha@yahoo.com \\ Dr. K.R.Sudha \\ Department of Electrical Engineering, Andhra University, Visakhapatnam, Andhra Pradesh, India \\ E-mail: arsudhaa@gmail.com \\ Swati Devabhaktuni \\ Department of Electrical Engineering, GokarajuRangaraju Institute of Engineering and Technology, Hyderabad, \\ Andhra Pradesh, India \\ E-mail:swatikjm@gmail.com
}

\begin{abstract}
Conventional street lighting systems in most of the areas are Online at regular intervals of time irrespective of the seasonal variations. The street lights are simply switched on at afternoon and turned off in the morning. The consequence is that a large amount of Power is wasted mean inglessly. As energy consumption is an issue of increasing interest, possible energy savings in public street lighting systems are recently discussed from different viewpoints. The purpose of this work is to describe the Smart Street Lighting system, an approach to accomplish the demand for flexible public lighting systems using a Programmable Logic controller (PLC). The main difference from other computers is that PLCs are armoured for severe conditions such as dust, moisture, heat, cold etc., and have the facility for extensive input/output (I/O) arrangements. In the proposed paper, street lights are controlled using millennium 3 PLC taking the seasonal variations into consideration.
\end{abstract}

Index Terms - Ladder Language, Functional Block Diagram (FBD), Timer

\section{Introduction}

Nowadays computer control and information system technology is applied widely in most of the process industry, because it may produce significant technical and economic benefits. Process control information systems assist operating personnel in producing the required output of products with minimum quality variations, least consumption of the raw material and energy, and maximum efficiency. Centralization process control combined with increased mechanization has resulted in improved productivity [1]. Now a day's advanced control systems like PLCs are extensively used in the industries.
Different control techniques have been proposed for street lighting controller during seasonal variation. It is common to use relays to make simple logical control decisions. The relays allow power to be switched on and off without a mechanical switch. The development of low cost computer has brought the most recent revolution, the Programmable Logic Controller (PLC).With the advent of the PLC, it has become the most common choice for manufacturing controls. A PLC is a digital operating electronic apparatus which uses a programmable memory for internal storage of instruction for implementing specific function such as logic, sequencing, timing, counting and arithmetic to control through analog or digital input/output modules various types of machines or process. There are different types of PLC'S used for various applications. In the present work, an XD 26 PLC is used to control the Street Lighting System.

The paper is organized as follows:

Section II presents the basic concepts of PLC. Section III gives an idea on the operating modes of the controller. The power control circuit is given in Section IV, while the Hardware Setup is presented in Section V. Finally, results are given in Section VI.

\section{Programmable Logic Controller}

Programmable Logic Controller is usually located in the field close to the processing unit. PLCs are small and operator interface may be simple as button switch. In second generation PLC suppliers have added analog to digital conversion capability and provided sufficient logic to configure simple control loops [2][3]. Presently there are at least two recognized PLC sizes:

- Small PLC, which is a relay replacement and provides a reliable control to stand-alone section of process and 
- Medium sized PLC that performs all the relay replacement functions expected of it, and also performs functions like counting, timing and complex mathe matical applications. Most medium sized PLCs can perform PID, feed forward, and control function as well. PLCs can now have date highway capabilities and can function as well in DCS environment.

There are five basic components in a PLC system:

- The PLC processor, or controller

- I/O (Input /Output) modules

- Chassis or backplane

- Power supply

- Programming software that runs in a PC

In addition to these 5, most PLCs also have:

- A network interface

Most PLCs have the ability to communicate with other devices. These devices include computers running programming software, or collecting data about the manufacturing process, a terminal that lets an operator enter commands into the PLC, or I/O that is located in a remote location from the PLC. The PLC will communicate to the other devices through a network interface.

Basic PLCs are available on a single printed circuit board .They are sometimes called single board PLCs or open frame PLCs. These are totally self-contained (with the exception of a power supply) and, when installed in a system, they are simply mounted inside a controls cabinet on threaded standoffs. Screw terminals on the printed circuit board allow for the connection of the input, output, and power supply wires.
These units are generally not expandable, meaning that extra inputs, outputs, and memory cannot be added to the basic unit. However, some of the more sophisticated models can be linked by cable to expansion boards that can provide extra I/O. Therefore, with few exceptions, when using this type of PLC, the system designer must take care to specify a unit that has enough inputs, outputs, and programming capability to handle both the present need of the system and any future modifications that may be required.

Single board PLCs are very inexpensive, easy to program, small, and consume little power, but, generally speaking, they do not have a large number of inputs and outputs, and have a somewhat limited instruction set. They are best suited to small, relatively simple control applications.

PLCs are also available housed in a single case (sometimes referred to as a shoe box) with all input and output, power and control connection points located on the single unit. These are generally chosen according to available program memory and required number and voltage of inputs and outputs to suit the application.

These systems generally have an expansion port (an interconnection socket) which will allow the addition of specialized units such as high speed counters and analog input and output units or additional discrete inputs or outputs. These expansion units are either plugged directly into the main case or connected to it with ribbon cable or other suitable cable.

PLCs were designed to eliminate the assembly line relays during model changeovers. The operation of PLC is easier than the relay panels. This feature reduces the installation and operational cost of the control system compared with the electromechanical relay systems [4]. PLC, highly reliable with a little maintenance, will communicate with the computer systems in the plant with a low investment cost. The basic block diagram of PLC systemis as shown in Fig.1.

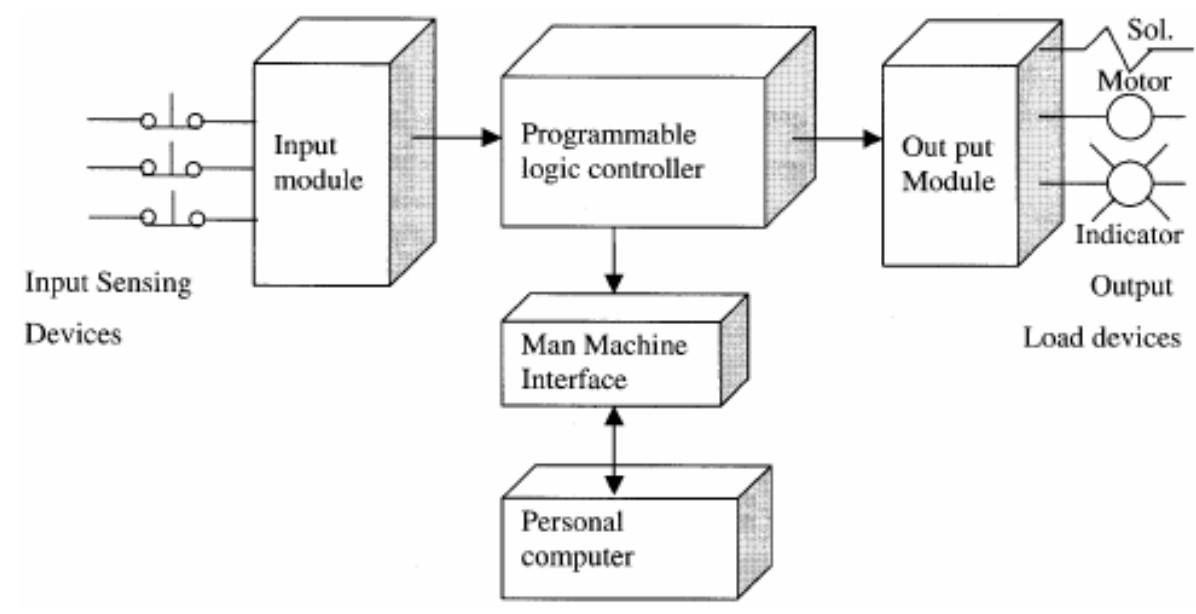

Fig. 1: Basic block diagram of PLC system 
PLCs are typically chosen for small discrete applications where high level ruggedness and reliability is required. They offer high speed sequential and logical control capabilities and are very good control solutions for real time applications. A PLC retains its operating system, user programs, and some data in retentive (nonvolatile) memory.PLC has not only replaces the relay but has also extended the logic capabilities of the system.

\subsection{Software Development}

In the present work, an XD 26 PLC [5] is used to control the Street Lighting System. The numbering for the XD 26 PLC is given in such a way that as it is having sixteen Digital of which six are analog inputs and ten discrete static relay outputs as shown in Fig.2.



Fig. 2: XD 26 PLC

Every PLC has associated programming software that allows the user to enter a program into the PLC. Before a PLC can perform any control task, it must be programmed to do so.

The Software used for the PLC is Crouzet Millenium 3 Programming Language. The controller offers two programming languages such as:

$>$ Ladder Language (LD)

$>$ Function Block Diagram (FBD)

$>$ Sequential Flow Chart (SFC)

$>$ Structured Text

$>$ Higher level languages such as C.

The first two of the above mentioned languages are discussed below.

\subsubsection{Ladder Language (LD):}

The most popular language used to program a PLC is ladder logic. Ladder Language (LD) is a graphic Language. It can be used to transcribe relay diagrams, and is suited to combinational processing. It provides basic graphic symbols: contacts, coils, and blocks. Specific calculations can be executed within the operation blocks.

\subsubsection{Function Block Diagram Language (FBD):}

FBD mode allows graphic programming based on the use of predefined function blocks. It offers a large range of basic functions: timer, counter, logic, etc

\subsection{Smart Street lighting}

Smart street lighting includes a total system with dimmable luminaires, advanced lighting control solutions, communication systems and administrative tools [6]. The solution focuses on low energy consumption and high functional standard. It also, in most contexts, automatically declines the maintenance costs for the operator in combination with increased safety for the street user.

In most cases Smart street lighting in its practical design is similar to adaptive lighting [7]. Anyway the difference between the two descriptions is that adaptive lighting only describes the performance of the light on the road, while s mart street lighting also includes the more operational elements, back office software solutions and both energy and lab our cost saving potentials. Streets or roads equipped with such a solution will dynamically adapt the street lighting performance according to the actual needs for the given period/time of the road.

Typically it will lead to lowered lumen output from the lamp during good conditions, when low traffic volumes or low average speed appears in combination with non-foggy weather. This will also be the case if the surface is covered with snow.

Over the last years new technology has been developed and implemented in multiple systems that can help to save even more energy.

Networking and automation technology allows for the adjustment of light levels to the exact need to keep the roads safe based on weather conditions, traffic density and other external factors. Telemanagement systems also account for significant savings in maintenance and increased safety because they instantly report failures in the system.

LED lighting also has great potential to help save energy in outdoor lighting. However the technology is still in the development phase and there is relatively very little experience with it at the moment. In this paper, taking all the above mentioned criterion into account, a PLC is proposed for the automatic street lighting control considering the seasonal variations. The various operating modes of the controller are discussed in the following section. 


\section{Operating Modes of the Controller}

A PLC executes an initialization step when placed in run mode, then repeatedly executes a scan cycle sequence. The basic PLC scan cycle consists of three steps an input scan, a user program scan, an output scan. The total time for one complete program scan is a function of processor speed, I/O modules used, and length of user program. Typically, hundreds of complete scans can take place in 1 second.

There are several operating modes for the program to simulate and monitor in the workspace. The various operating modes are listed below:

- Edit Mode: Edit mode is used to construct programs in FBD mode, which corresponds to the development of the application.

- Simulation Mode: In simulation mode, the program is executed offline directly in the programming workshop .In this mode, each action on the chart (changing the state of an input, output forcing) updates the simulation windows.

- Monitoring mode: In Monitoring mode, the program is executed on the controller and, the programming works pace is connected to the controller.

PLC's programming is based on the logic demands of input devices and the programs implemented are predominantly logical rather than numerical computational algorithms [15]. Most of the programmed operations work on a straightforward twostate on or off basis and these alternate possibilities correspond to true or false (logical form) and 1 or 0 (binary form),respectively. Thus, PLCs offer a flexible programmable alternative to electrical circuit relaybased control systems built using analog devices [16].

The programming method used is the ladder diagram method. The PLC system provides a design environment in the form of software tools running on a host computer terminal which allows ladder diagrams to be developed, verified, tested, and diagnosed[17]. First, the high-level program is written in ladder diagrams. Then, the ladder diagram is converted into binary instruction codes so that they can be stored in randomaccess memory (RAM) or erasable programmable readonly memory (EPROM). Each successive instruction is decoded and executed by the CPU [8][9].

The function of the CPU is to control the operation of memory and I/O devices and to process data according to the program. Each input and output connection point on a PLC has an address used to identify the I/O bit [18] The method for the direct representation of data associated with the inputs, outputs, and memory is based on the fact that the PLC memory is organized into three regions: input image memory (I), output image memory $(\mathrm{Q})$, and internal memory $(\mathrm{M})$.
The PLC program uses a cyclic scan in the main program loop such that periodic checks are made to the input variables [19]. The program loop starts by scanning the inputs to the system and storing their states in fixed memory locations (input image memory I). The ladder program is then executed rung-by-rung.

Scanning the program and solving the logic of the various ladder rungs determine the output states. The updated output states are stored in fixed memory locations (output image memory Q) [20].

The output values held in memory are then used to set and reset the physical outputs of the PLC simultaneously at the end of the program scan. For the given PLC, the time taken to complete one cycle or the scan time is $0,18 \mathrm{~ms} / \mathrm{K}$ (for 1000 steps) and with a maximum program capacity of 1000 steps. The development system comprises a host computer (PC) connected via an RS232 port to the target PLC [10].

The host computer provides the software environment to perform file editing, storage, printing, and program operation monitoring. The process of developing the program to run on the PLC consists of: using an editor to draw the source ladder program, converting the source program to binary object code which will run on the PLC' $\mathrm{s}$ microprocessor and downloading the object code from the PC to the PLC system via the serial communication port [11][12]. The PLC system is online when it is in active control of the machine and monitors any data to check for correct operation.

In the present work, the program is developed in the Function Block Diagram Mode, since it has the components or the blocks which are pictorially understood and easy for verification.

\section{Power control Circuit}

The Power control circuit diagram is shown in Fig.3.

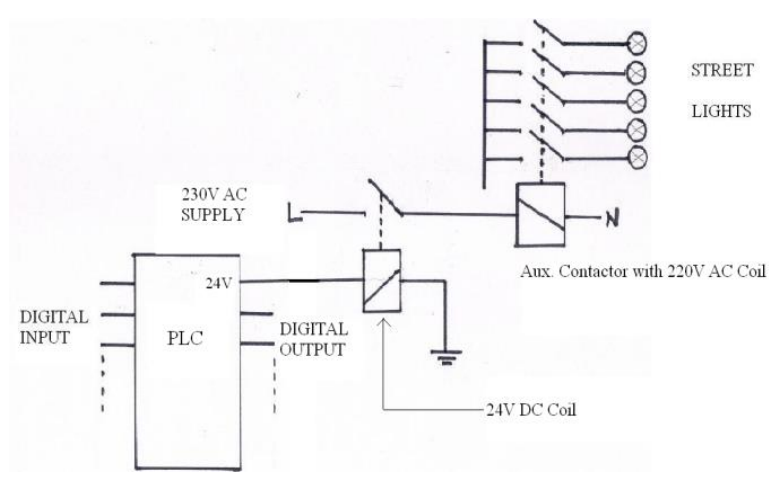

Fig. 3: Power Control Circuit

It is clearly observed that the input given to the PLC is nothing but the timer inputs. Here the timer inputs refer to the time at which the street lights should be made ON and OFF. Since we know that this XD 26 
PLC gives an output of $24 \mathrm{~V}$ DC. As the output is connected to the $24 \mathrm{~V} \mathrm{DC}$ Coil, and this Coil gets energized and the Line to Neutral contactor gets closed. When the contactor is closed a $230 \mathrm{~V}$ AC Supply flows through the auxiliary Contactor with $220 \mathrm{~V}$ A C Coil. As a result this auxiliary Contactor gets active and then the Street Lights are ON [13][14][15].

\section{- Simulation Procedure:}

In this program the main component used is the TIMER PROG block, which contains weeks, months and years. It also consists of the Cycles i.e, the period for the execution of the program.
The procedural steps involved in the process of simulation are given below:

1. The Functional block diagram is constructed using the TIMER PROG Block which actually gives the information on whether the SUMMER/WINTER time Change is active or Inactive. This can be checked by clicking on the PROGRAM CONFIGURATION BLOCK. The Day and Month of the change of season from summer to winter and similarly from the winter to summer can be mentioned on the DATE FORMAT Task Bar as shown in the Fig.4.



Fig. 4: Program Configuration

2. The next step is to select the PARAMETERS Task Bar of B02 TIMER PROG Block. During summer the durations of time for which the Street Lights to be made ON and OFF are set in this block. Similarly for the B04 TIMERPROG Block the ranges of time for which the street lights should be made on or off during winter season are set as shown in Fig.5.

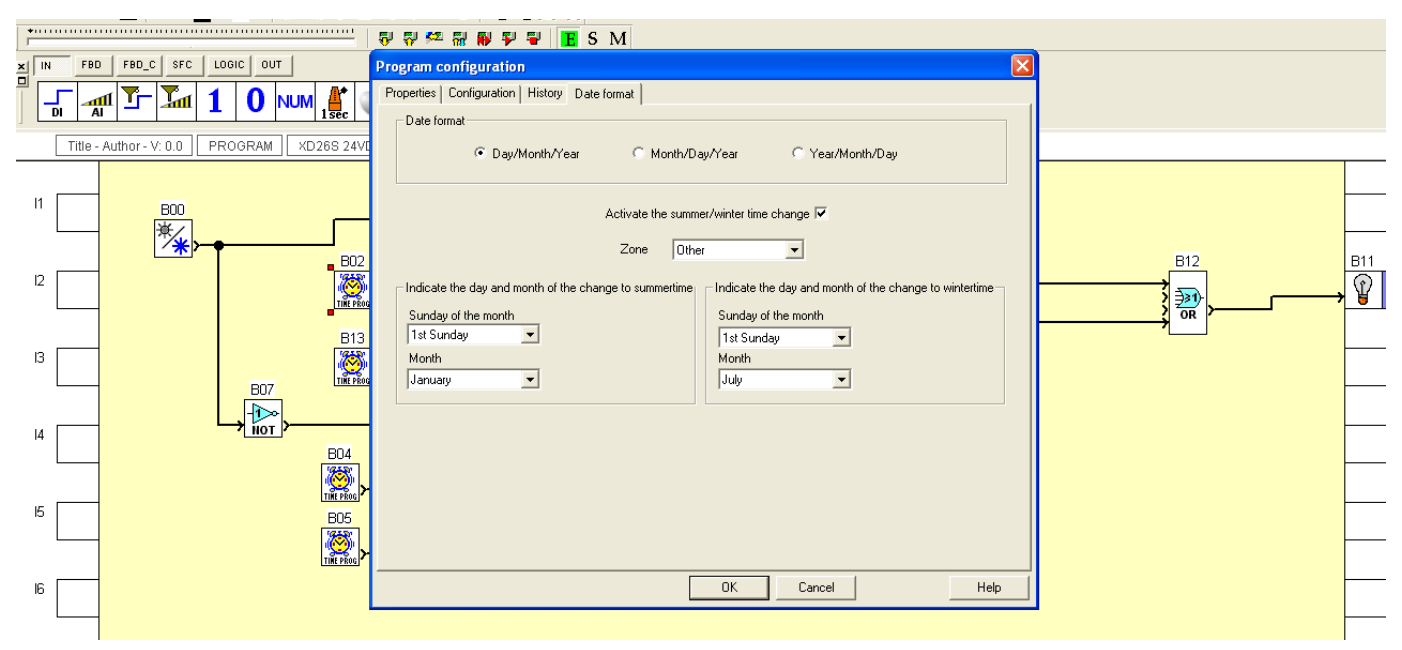

Fig. 5: Timer program block

3. After setting the values in the TIMER PROG block, the remaining block diagram is constructed using TIMER A-C blocks as shown in Fig.6. 


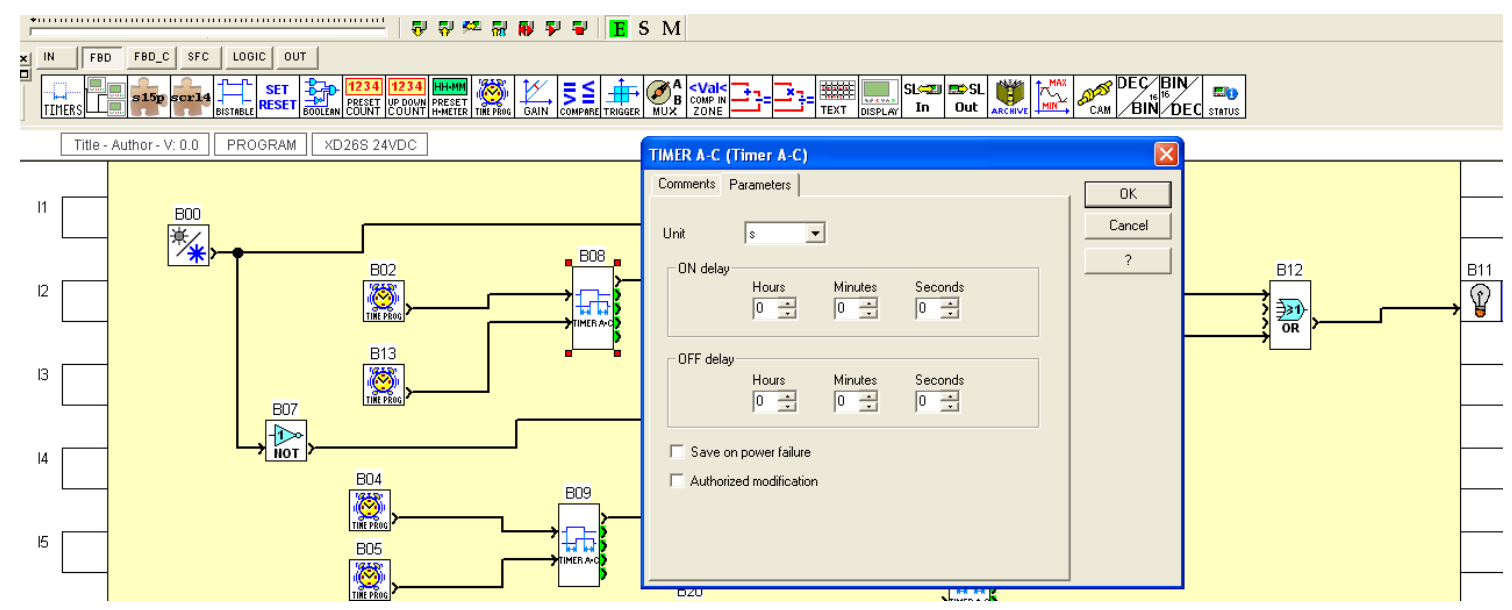

Fig. 6: Timer A-C Block Configuration

4. Finally when all these values in the respective blocks are set, the program is simulated. The simulation is done with the PLC software and the hardware setup is made. The program is written according to the season's summer and winter and the lights will glow according to the season's.

\section{Hardware Setup}

The Street Lighting Controller is modelled and simulated using Crouzet Milleniu m 3 PLC as shown in Fig.7.The panel behind the PC represents Crouzet Millenium PLC. An 8-Channel Relay Module, CrouzetMillenium PLC (Programmable Logic Controller),

Power Supply Module are shown on the panel. Power supply (24V-DC) is connected to Crouzet Millenium PLC. The Input/output pins in PLC are connected to the respective relays pins in Relay Module. The lights are switched to ON/OFF according the seasons.



Fig. 7: Hardware Setup

\section{Results}

In the simulation mode of the PLC, ON and OFF periods for the Street Lights are tested during summer seasons. The results obtained during simulation are shown in Fig.8 and Fig.9.In summer season the lights will glow in late night and will switch OFF so early.

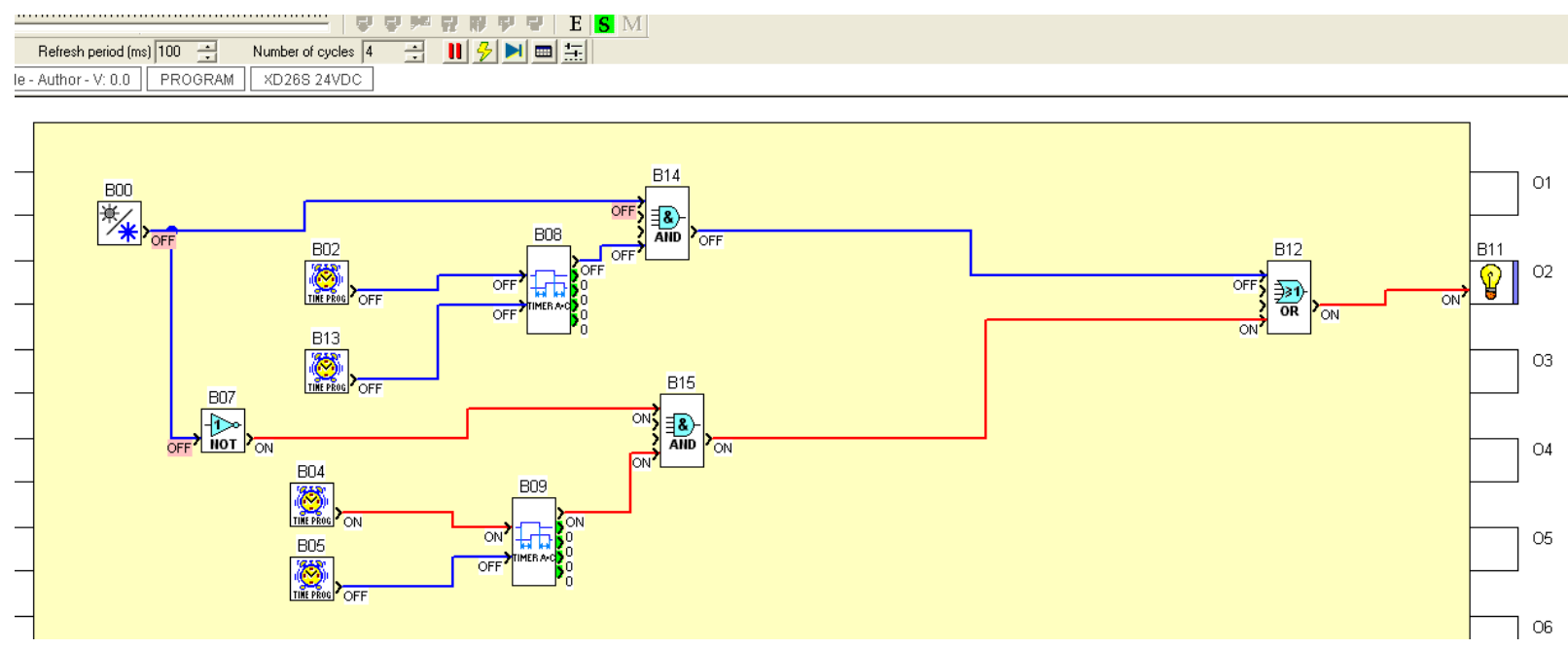

Fig. 8: Simulation Mode in ON time during summer 


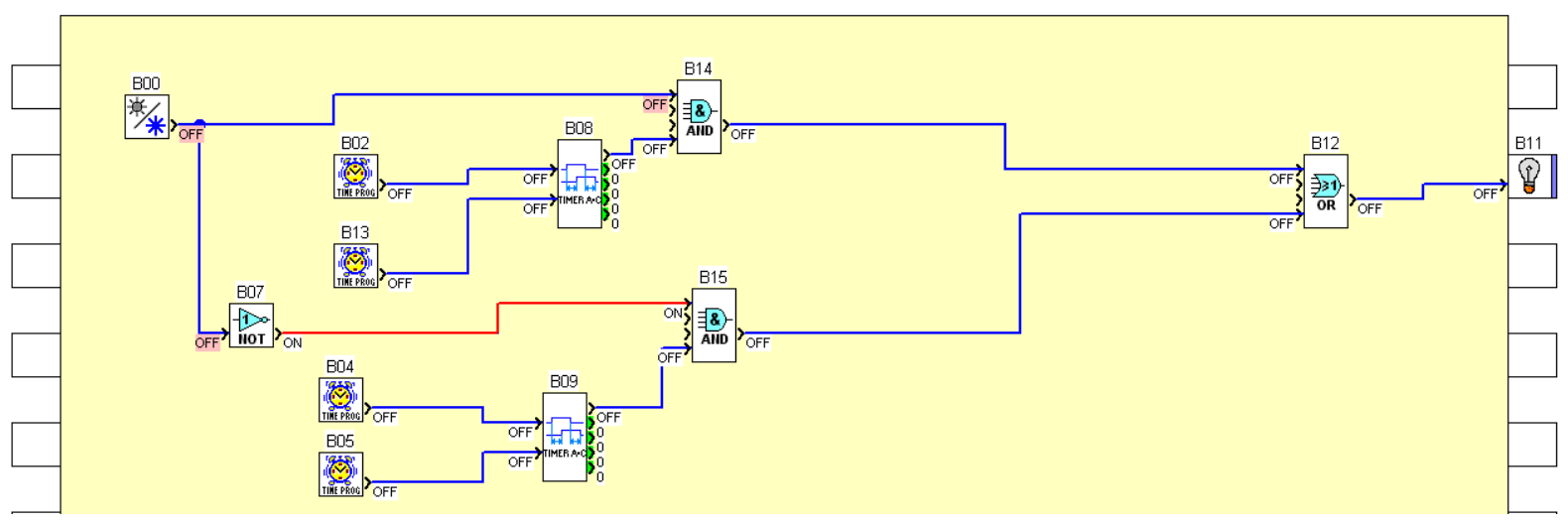

Fig. 9: Simulation Mode in OFF time during summer

Since in the winter season, the street lights should be switched on early when compared to the summer season, the required timings are set in the TIMER PROG block.
The SIMULATION for the winter seas on has carried out and the ON and OFF times are verified as shown in Fig.10 and Fig. 11 respectively.

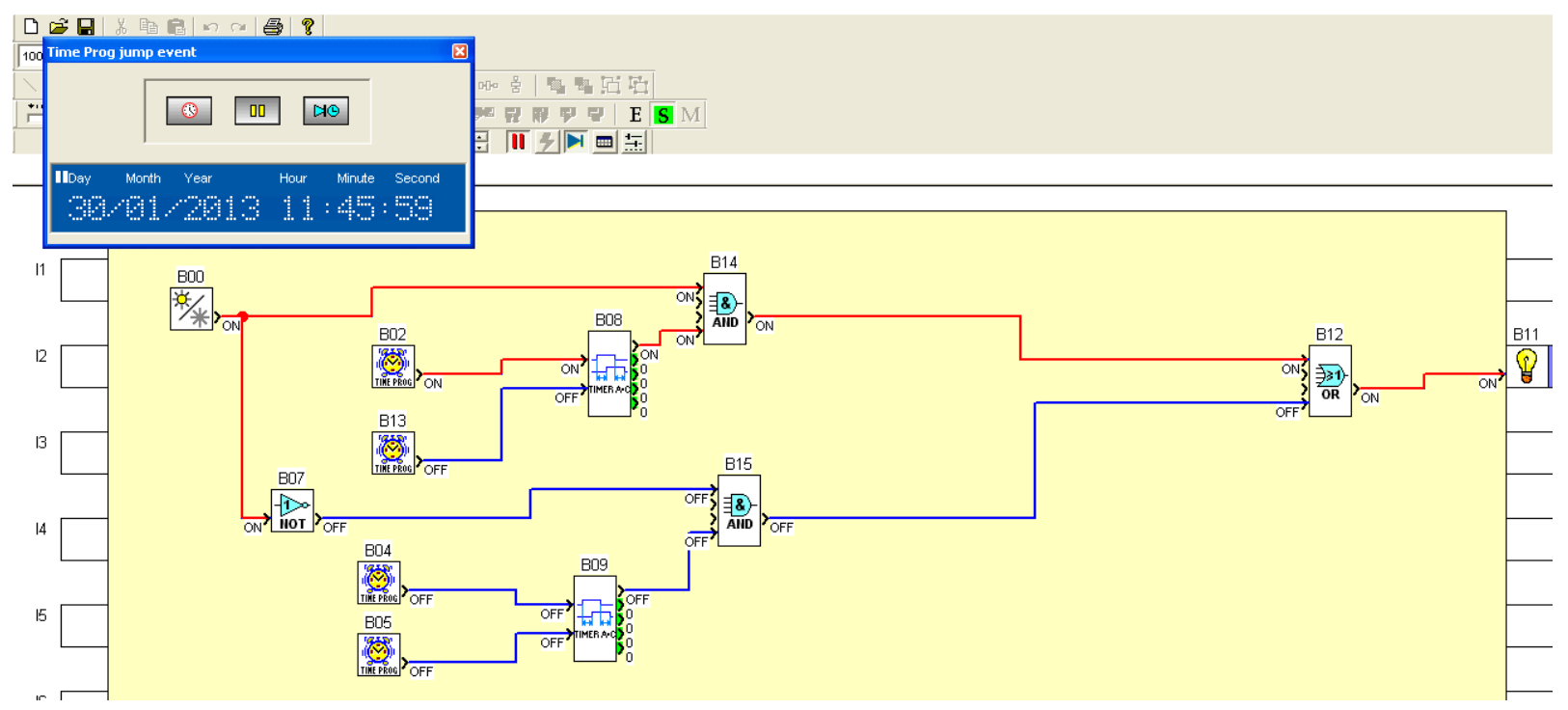

Fig. 10: Simulation Mode in ON Time during winter

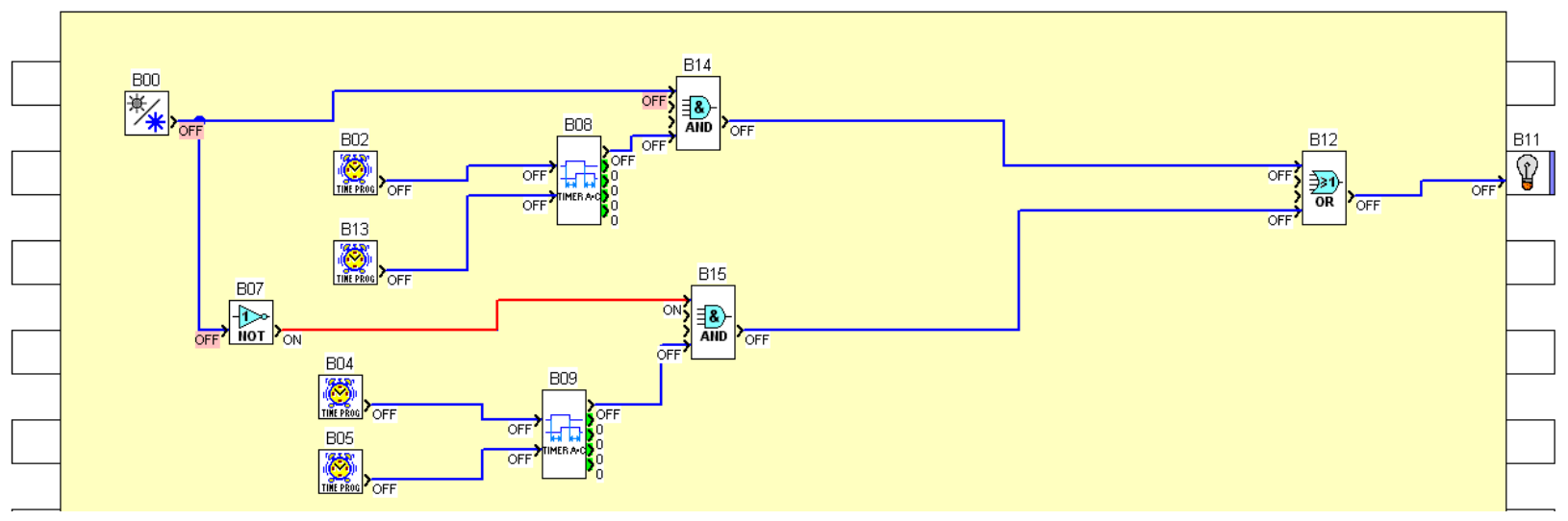

Fig. 11: Simulation Mode in OFF Time during winter 


\section{Conclusions}

In this paper, an approach for controlling Street Lighting system using millennium 3 PLC is proposed. The proposed controller gives fast, reliable, and power efficient street lamp switching based on seasonal variations. The simulated results are also verified experimentally by using a light dependent resistor (LDR) which senses the light. LDR is used as the replacement for the seasonal variation. This paper confirms that the proposed PLC based street lighting control system has great potential to revolutionize street lighting which in turn saves large amount of power.

\section{Acknowledgments}

We thank the Department of Electrical Engineering, Gokaraju Rangaraju Institute of Engineering and Technology, Hyderabad for rendering their support and providing the facilities to setup the hardware circuit for the work proposed in this paper.

\section{References}

[1] E. El-Shirbeeny "Proposal for automating street lighting system of Abu Dhabi/AI Ah highway", EPRL01-1, ADWEA, Abu Dhabi, UAE, 2001

[2] Pantoni, R.P.; Brandao, D. "A geocast routing algorith $\mathrm{m}$ intended for street lighting system based on wireless sensor networks", , 2010 9th IEEE/IAS International Conference on Industry Applications (INDUSCON), On page(s): 1 - 6

[3] Reluz Program (Jan. 2010). "National Program of Efficient Public Lighting and Traffic Lights". Available: http://www.eletrobras.gov.br/EMProgramas-Reluz .

[4] Ei-Shirbeeny, E.H.T.; Bakka, M.E. "Experimental pilot project for automating street lighting system in Abu Dhabi using powerline communication". Proceedings of the 10th IEEE International Conference on Electronics, Circuits and Systems. Vol. 2, p.743 - 746, Dec. 2003.

[5] Crouzet millennium 3 PLC manual- 2013 Sungkwan C.; Dhingra, V. "Street lighting control based on Lon Works power line communication Power Line Communications and Its Applications". IEEE Symposium, 2008.

[6] Streetlight Intelligence (Jan. 2010). Available: http://www. streetlightiq.comDenardin,

[7] G.W.; Barriquello, C.H.; Campos, A. Do Prado, R.N. "An Intelligent System for Street Lighting Monitoring and Control". 10 Congresso Brasileiro de Eletrônica de Potência. Brasil, Bonito, 2009.

[8] Caponetto, R., Dongola, G., Fortuna, L., Riscica, N. and Zufacchi, D. (2008), "Power consumption reduction in a remote controlled street lighting system", International Symposium on Power Electronics, Electrical Drives, Automation and Motion (SPEEDAM 2008), Ischia, 11-13 June, pp. 428-33.

[9] Chen, P.-Y., Liu, Y.-H., Yau, Y.-T. and Lee, H.-C. (2008), "Development of energy efficient street light driving system", IEEE International Conference on sustainable Energy Technologies(ICSET 2008), Singapore, 24-27 November, pp. 761

[10] Chung, H.S.H., Ho, N.M., Hui, S.Y.R. and Mai, W.Z. (2005), "Case study of a highly-reliable dimmable road lighting system with intelligent remote control", paper presented at European Conference on Power Electronics and Applications, Dresden.

[11] E. El-Shirbeeny, "Pilot project far using powerline communications in controlling street lighting" Report, EPRL01-21, ADWEA, Abu Dhabi, UAE, 2001.

[12] E. El-Shirbeeny, "Pilot project far using powerline communications in controlling street lighting" Report, EPRL01-21, ADWEA, Abu Dhabi, UAE, 2001.

[13] Pantoni, R.P.; Brandao, D. "A confirmation-based geocast routing algorithm for street lighting system", Industrial Electronics (ISIE), 2011 IEEE International Symposium on, On page(s): 841 846

[14] An energy efficient pedestrian aware Smart Street Lighting system Reinhard $\mathrm{Mu}$ "llner and Andreas Riener Institute for Pervasive Computing, Johannes Kepler University Linz, Linz, Austria,International Journal of Pervasive Computing and Communications Vol. 7 No. 2, 2011 pp. 147-161.

[15] Powerline Communications for Street Lighting Automation By: Scot Robertson, Executive Business Manager for Powerline Products Mar 27, 2012.

[16] Wang, C. ; Zhang, D.L. ; Qin, H.L. ; Yao, Y.Y.Sun, Y. ; Shen, Y., "HPS Street Lighting Lamp Networking over Power-lines", PowerCon 2006, International Conference on Power System Technology, Oct. 22-2, Page(s): 1 - 5.

[17] Economakos, C. ; Economakos, G., "FPGA implementation of PLC programs using automated high-level synthesis tools",ISIE 2008. IEEE International Sy mposiu m on Industrial Electronics, 2008, Page(s): 1908 - 1913.

[18] Li-Ling Wang, Hong-Ying Wei, "Development of a distributed control system for PLC-based applications" International Conference on Machine, 2010, Volume:2, Page(s): 906 - 909. 
[19] Prof. K.Y.Rajput, Gargeyee Khatav, Monica Pujari, Priyanka Yadav4," Intelligent Street Lighting System Using Gsm", International Journal of Engineering Science Invention ISSN (Online): 2319 - 6734, Volume 2 Issue 3 || March. 2013 || PP.60-69

\section{Authors' Profiles}

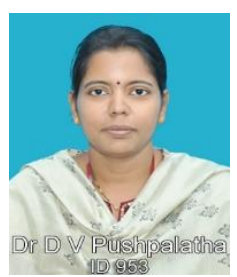

Dr. D.V.Pushpalatha is working as a Professor in the Department of Electrical and Electronics Engineering at Gokaraju Rangaraju Institute of Engineering and Technology, Hyderabad, A.P., India. She holds a degree in Bachelor of Engineering (B.E.) with specialization in Electrical \& Electronics from Andhra University (GITAM College, Visakhapatnam), Master of Engineering (M.E.) with specialization in Control Systems Engineering from Andhra University and performed a research in Control Systems resulting in a Ph.D from Andhra University, Visakhapatnam, A.P., India. She has keen interest in the field of research spanning embedded systems, Fuzzy Logic and Support Vector Machines.

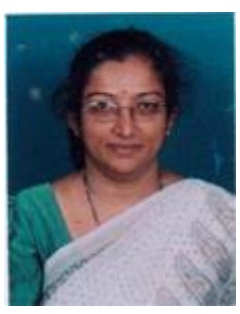

Dr. K.R.Sudha is working as a Professor in the Department of Electrical Engineering at Andhra University (A), Vis akhapatnam, A.P., India. She holds a degree in Bachelor of Engineering (B.E.) with specialization in Electrical \& Electronics from Andhra University (GITAM College, Visakhapatnam), Master of Engineering (M.E.) with specialization in Power Systems \& Automation Engineering from Andhra University and performed a research in Power Systems resulting in a Ph.D from Andhra University, Visakhapatnam, A.P., India. She has keen interest in the field of research spanning embedded systems, Fuzzy Logic and Support Vector Machines. She handled many projects in the above mentioned areas of research.

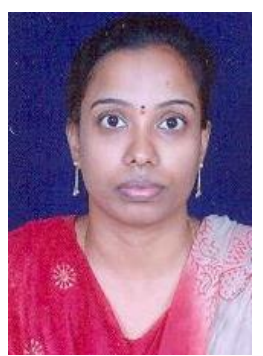

Swati Devabhaktuni received the B.Tech degree in electrical and electronics engineering from V. R. Siddhartha Engineering College, Andhra University, India in 2001, and the M.Tech degree in control systems from J.N.T.U University, in 2004. Currently, she is a Associate professor in Gokaraju rangaraju Institute of engineering and technology, Hyderabad, She is also a Research Scholer in J.N.T.U University, Hyderabad. Her research interests are the power electronics, AC motor drives, and control systems.

How to cite this paper: D.V.Pushpa Latha, K.R.Sudha, Swati Devabhaktuni,"PLC based Smart Street Lighting Control", International Journal of Intelligent Systems and Applications(IJISA), vol.6, no.1, pp.64-72, 2014. DOI: 10.5815/ijisa.2014.01.08 